\title{
Erratum: Background perspectives on infinity and God
}

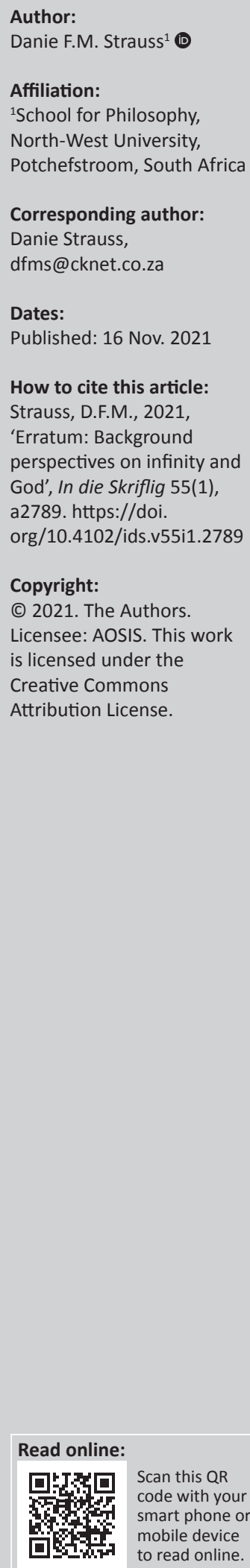

In the published article, Strauss, D.F.M., 2019, 'Background perspectives on infinity and God', In die Skriflig 53(1), a2421. https://doi.org/10.4102/ids.v53i1.2421, there was an error in the affiliation. Instead of 'Department Philosophy, University of the Free State, Bloemfontein, South Africa', it should be 'School for Philosophy, North-West University, Potchefstroom, South Africa'.

This correction does not alter the study's findings of significance or overall interpretation of the study results. The publisher apologises for any inconvenience caused. 